\title{
INFLUENCE OF INTESTINAL SURFACTANT LIKE PARTICLES ON DIFFERENTIAL ACTIVATION OF SECONDARY SIGNALING MOLECULES DURING SALMONELLA TYPHIMURIUM INFECTION
}

\author{
M. HANIEF SOFI ${ }^{1,2,3,4}$, ARCHANA BHATNAGAR ${ }^{1,2}$, SAVEETA SAPRA ${ }^{1}$, \\ AKHTAR MAHMOOD ${ }^{2}$ and SIDHARTHA MAJUMDAR ${ }^{1}$ \\ ${ }^{1}$ Department of Experimental Medicine \& Biotechnology \\ Postgraduate Institute of Medical Education and Research (PGIMER) \\ Chandigarh, India \\ ${ }^{2}$ Department of Biochemistry \\ Panjab University \\ Chandigarh, India \\ ${ }^{3}$ Department of Microbiology and Immunology \\ University of Michigan School of Medicine \\ Ann Arbor, MI 48109
}

Accepted for Publication July 8, 2009

\begin{abstract}
Interaction between the enteric pathogen Salmonella typhimurium and the luminal surface of the intestine provoke an acute inflammatory response mediated in part by various inflammatory molecules. Surfactant-like particles (SLP) are known to cover the surface of the intestinal epithelium, act as lubricants and/or as a vehicle to deliver digestive enzymes to the luminal fluid. Recently we have shown that SLP plays an important protective role during microbial insult. The data suggested that SLP-induced diet prevents the damage of intestinal villi caused by $\mathrm{S}$. typhimurium infection. The present study was designed to assess the role of SLP on secondary signaling molecules during S. typhimurium infection. The Peyer's patch, intraepithelial and lamina propria mononuclear cells were analyzed under various conditions for secondary signaling molecules, including calcium, inositol triphosphate and protein kinase C. SLP-induced diet along with infection showed significant variation in these secondary signaling molecules, particularly in Peyer's patches, as compared to infection group alone. In addition, the cells isolated from the infected group upon incubation in vitro with SLP also showed a considerable variation of these molecules. These results suggested an impor-

${ }^{4}$ Corresponding author. TEL: 734-647-7579; FAX: 734-764-3562; EMAIL: mhanief@umich.eduf
\end{abstract}


tant influence of SLP on secondary signaling molecules and, in turn, could be important in overall immune modulation during infection.

\section{PRACTICAL APPLICATIONS}

Salmonella are known to cause disease in humans, animals and birds worldwide. Over 1.4 million cases of salmonellosis (gastroenteritis) per year occur in the U.S.A. and other industrialized countries. Countries with poor sanitation have a much higher incidence of salmonellosis. The disruption of epithelial barrier integrity by Salmonella has pathological consequences. Intestinal epithelium secretes surfactant-like particles (SLP); these particles have the ability to cover the surface of the cell in the intestinal lumen. They are known to have ability in binding of uropathogenic Escherichia coli and in protecting the disruption of intestinal villi. The present study provides further evidence for its role in regulating secondary signaling molecules and overall immune response. SLP induced by dietary fat enhanced the resistance to intestinal infections, as it possibly decreases the colonization and translocation of S. typhimurium. The SLP and microbe interaction may thus represent a delicate balance between symbiosis and pathogenesis.

\section{INTRODUCTION}

Pathogenic microbes subvert normal host-cell processes to create a specialized niche, which enhances their survival. A number of enteric pathogens are known to perturb the intestinal epithelial barrier by mechanisms, which may be unique for different pathogens (Sears 2000). Previous reports have shown that invasion of polarized human intestinal epithelial cells by Salmonella typhimurium is associated with rapid molecular changes in the composition of tight junctional complexes, leading to the loss of barrier function. The disruption of epithelial barrier integrity by Salmonella has pathological consequences by enhancing bacterial translocation across the epithelial barrier, and fosters disease pathology by promoting the migration of polymorphonuclear leukocytes (Kohler et al. 2007)

Intestinal epithelium secretes unique lipoprotein lamellar structures, which are rich in phosphatidyl choline and intestinal alkaline phosphatase (IAP), and have the buoyancy characteristics similar to lung surfactants. These lamellar structures are called surfactant-like particles (SLP) (Mahmood et al. 2003). These particles have the ability to lower the surface tension of intestinal epithelial cells and contain small amounts of surfactant specific proteins A, B and D. In the intestinal lumen, they seem to cover the surface of the cell, where 
they may act as lubricants and/or as a vehicle to deliver digestive enzymes to the luminal fluid (Mahmood et al. 2003). These particles have also been found to have the ability in binding of uropathogenic Escherichia coli (Goetz et al. 1999) Also, the decrease in SLP in active duodenal ulcer or duodenitis suggests that SLP is consumed by inflammatory process, or that the synthesis/ secretion of the SLP was altered. Such a change in SLP content might play a part in the pathogenesis of duodenal ulcer disease (Eliakim et al. 1996).

Recently, we have shown that SLP plays very important immunomodulatory role during Salmonella infection (Sofi et al. 2007). In addition, electron microscopic studies from the same report have shown that microvilli was damaged from S. typhimurium-infected rat intestine while it was intact, but with edema when rats infected with S. typhimurium along with SLPinduced diet was given, suggesting a protective role of SLP during infection.

The variation in various cytokines is associated with the change in signaling and secondary signaling molecules. Previous reports with S. typhimurium indicate that an increased $\left[\mathrm{Ca}^{2+}\right] \mathrm{i}$ is involved in up-regulating synthesis of the proinflammatory cytokines (Gewirtz et al. 2000). In addition, the involvement of protein kinase $\mathrm{C}$ (PKC) was also observed during bacterial infection. The present study was designed to see the influence of SLP on these secondary signaling molecules in the presence and absence of infection. We proposed that SLP regulates secondary signaling molecules during Salmonella infection. So to better understand the mechanism, we analyzed these secondary signaling molecules under the conditions mentioned earlier. The payer's patch (PP), intraepithelial (IE) and lamina propria (LP) mononuclear cells were isolated from various groups (as mentioned in Materials and Methods). We found a significant variation in these signaling molecules in the presence and absence of SLP-induced diet, suggesting that SLP plays an important role in regulating secondary signaling molecules, which finally have greater impact on cytokine status and on overall immune response.

\section{MATERIALS AND METHODS}

\section{Laboratory Animals}

In the present study, Sprague-Dawley rats with body weight ranging from 150 to $180 \mathrm{gm}$ were procured from the central animal house Postgraduate Institute of Medical Education and Research (PGIMER), Chandigarh, India. They were housed in individual cages, acclimatized to the laboratory conditions and fed with standard pellet diet and water ad libitium. They were also administered a course of broad-spectrum antibiotics and anti-helminthic drugs to take care of previous bacterial or parasitic infections. For the following 1 
month, the rats were strictly fed on autoclaved diet and water. The animals were divided into four groups: control, animals fed fat diet only, animals fed fat diet and infection, and animals on infection only. Each group had 10 rats. This study was granted ethical clearance by the local animal committee of PGIMER.

Infection: S. typhimurium was used as an infecting agent and was maintained in the laboratory in nutrient broth medium. This pathogenic, invasive strain (ATCC 14028s) was obtained from MTCC (Institute of Microbial Technology, Chandigarh-160039, India). S. typhimurium was grown in nutrient broth $\mathrm{O} / \mathrm{N}$ at $37 \mathrm{C}$; in the log phase, bacterial culture was harvested, suspended in normal saline and the viability of the bacteria was determined by the spread plate technique. The lysate of $S$. typhimurium used in the experiments was prepared by sonication of the bacteria (in the previously mentioned conditions) for 2-3 min. The protein content of the lysate was estimated by Lowry's method (1951) (Lowry et al. 1951). A $6 \mu \mathrm{g}$ amount of lysate was added per well $/ \mathrm{mL}$.

\section{Determination of Viable Counts of Bacteria (CFU) and Mode of Infection}

S. typhimurium was grown aerobically in nutrient broth overnight at 37C. Bacterial cultures were harvested, washed and suspended in normal saline. Viable counts were determined by spread plate technique. Serial 10-fold dilution of known number of bacteria/mL was made with sterile normal saline, and from each dilution, $10 \mathrm{ml}$ of bacterial inoculum was incubated in nutrient broth (Difco, Lawrence, KS) and was plated out and incubated at 37C overnight. The colonies were counted after $\mathrm{O} / \mathrm{N}$ incubation, and $\mathrm{CFU}$ was calculated. In the log phase of bacteria, the number of cells counted after plating was $10^{7}$ cells $/ \mathrm{mL}$ of broth. This was taken as a standard for infecting the rats under different conditions.

Rats were given $0.25 \mathrm{~mL}$ of a solution of $0.2 \mathrm{M} \mathrm{NaHCO}_{3}$ orally through gastric gauges to neutralize acidity (Zhang and Stanley 1996), and after waiting for $5 \mathrm{~min}, S$. typhimurium $\left(2 \times 10^{7} \mathrm{cfu} / 1 \mathrm{~mL}\right)$ was administered through gastric gauge (Powell et al. 1971). Animals had free access to water but were not allowed to eat for $24 \mathrm{~h}$ before giving infection, as well as before the sacrifice.

\section{Isolation of Surfactant-Like Particles from Rat Intestine}

The SLP were isolated by the method of Eliakim et al. (1989) Briefly, male Sprague-Dawley rats fasted overnight were fed with corn oil intragastrically and then sacrificed after 5-7 h of feeding. The intestine was opened longitudinally, and the mucosal surface was lightly scraped using Whatman 
No. 3 paper and suspended in solution A ( $5 \mathrm{mM}$ Tris [hydroxy methyl] amino methane buffer, $\mathrm{pH} 7.4$, containing $5 \mathrm{mM} \mathrm{CaCl}_{2}$ ).

Gradient centrifugation: SLP were isolated from the light mucosal scrapings by passing through a gradient that separated membrane bound phosphatase (density 1.07-1.08 g/L) from free IAP (density $1.057 \mathrm{~g} / \mathrm{L}$ ). The mucosal scrapings from the fat fed group were fractionated on continuous $\mathrm{NaBr}$ gradients (0.49-1.49 $\mathrm{M}$ in solution A). A visible white band of density $1.07-1.08 \mathrm{~g} / \mathrm{L}$ was formed against clear solution after centrifugation at $100,000 \times \mathrm{g}$ for $16 \mathrm{~h}$ at $5 \mathrm{C}$ using an SW-41 rotor (Beckman Instruments, Philadelphia, PA). These conditions were identical to those used by Eliakim et al. (1989) to isolate rat intestinal SLP. One-milliliter fractions were removed from the top of the gradient by siphoning and used for biochemical analysis. Fractions 3 and 4, exhibiting maximal IAP activity, were pooled from several gradients, dialyzed and concentrated using an Amicon filter (XM-10) assembly (Millipore Corp., Bedford, MA). This SLP isolated from rats that were only given a fat diet was used throughout the experiments. The SLP from a control group of rats not given a fat diet was isolated separately and used as control throughout the experiments.

\section{Estimation of Activity of Alkaline Phosphatase}

The activity of alkaline phosphatase was estimated by using the method of King and Amstrong 1934). Briefly, sodium carbonate-bicarbonate buffer was added to different tubes labeled as blank, control, standards and tests. The different concentrations of test samples of all four different groups were added to test and control tubes only. Different concentrations of standards were also added to the tubes labeled as standards. The water was added to make up the volume of all tubes. Then, sodium hydroxide was added to the tubes labeled with controls. However, the substrate was added to all tubes and was incubated at $37 \mathrm{C}$ in a water bath for $15 \mathrm{~min}$. Later, sodium hydroxide was added to all tubes except the control ones. Finally, sodium bicarbonate, 4-amino antipyrine and potassium ferricyanide, respectively, were added to all tubes and incubated for $10 \mathrm{~min}$. Absorbance was read at 510 .

\section{Isolation of PP, IE and LP Mononuclear Cells}

The methods of Davis and Parrot (Davies and Parrott 1981) and Lyscom and Bruetion (Lyscom and Brueton 1982) were used for isolation. Briefly, after rats were sacrificed. They were anesthetized with anesthetic ether and killed by cervical dislocation. The small intestine was immediately removed, flushed with citrate buffer and slit open. The PP was carefully dissected out. The cells were released from the PP by scraping with a scalpel. The intestine was then opened longitudinally and cut laterally into small pieces $(0.5-1 \mathrm{~cm})$. These 
pieces were put into a flask containing citrate buffer/bovine serum albumin (BSA) and were incubated for $30 \mathrm{~min}$ at $37 \mathrm{C}$ in a shaking water bath, followed with vigorous shaking for $15 \mathrm{~s}$ on vortex. The supernatant fluid was removed and replaced, and the shaking process was repeated until the supernatant fluid was clear and the intraepithelial lymphocytes (IEL) were collected. The tissue fragments were incubated for an additional 30 min, shaking at 37C in hank's balanced salt solution (HBSS) with $1 \mathrm{mM}$ dithiothreitol and 5mMM ethylenediaminetetraacetic acid, and the remaining IEL/enterocytes were discarded. The remaining tissue was incubated for $20 \mathrm{~min}$ with stirring in presence of collagenase to facilitate the disruption of the gut pieces. Then, the supernatant was collected and repeated the same until the supernatant was found clear. The PP, IE and LP mononuclear cells in citrate buffer/BSA were filtered through cotton gauze to remove coarse clumps and subsequently passed through cotton wool filters. The cells were further purified by Ficoll isopaque. Cell recovery and viability was determined by trypan blue exclusion ( $0.05 \%$ in saline) using a hemocytometer counting chamber.

\section{Intracellular $\mathrm{Ca}^{2+}$ Levels by Flow Cytometry}

Intracellular $\mathrm{Ca}^{2+}$ levels were estimated using Fluo 3/AM by the method described by Minta et al. (Minta et al. 1989). Briefly, mononuclear cells $\left(1 \times 10^{6} / \mathrm{mL}\right.$ of Roswell Park Memorial Institute (RPMI)-1640 medium) were incubated at 37C for 20 min with $4 \mu \mathrm{M}$ Fluo 3/AM (Molecular Probes, Eugene, OR). The reaction mixture was diluted five times with RPMI-1640 medium containing $1 \%$ fetal calf serum and incubated for $40 \mathrm{~min}$ at $37 \mathrm{C}$. The cells were then washed three times and re-suspended in RPMI-1640 medium prewarmed to 37C. Cells were subsequently stimulated with either $6 \mathrm{mg} \mathrm{S}$. typhimurium lysates or $6 \mathrm{mg}$ SLP or both and were analyzed on chronys software on flow cytometry. Throughout the experiments, temperature was strictly maintained at $37 \mathrm{C}$.

\section{Inositol Triphosphate Turnover $\left(\mathrm{IP}_{3}\right)$}

IP3 turnover was measured by the method of Oldham 1990). Briefly the cells were labeled with $0.5 \mu \mathrm{Ci}$ of myo $\left[{ }^{3} \mathrm{H}\right]$-inositol (Amersham Life Science, Piscataway, NJ, TRK883 B42) in tissue culture flask and incubated for $18 \mathrm{~h}$ at $37 \mathrm{C}$ in a $\mathrm{CO}_{2}$ incubator. After incubation, the cells were washed twice with medium and were collected by centrifugation at $250 \times \mathrm{g}$. The cells were subsequently incubated at $37 \mathrm{C}$ with $10 \mathrm{~mm} \mathrm{LiCl}$ for $15 \mathrm{~min}$ and were stimulated with either $6 \mathrm{mg}$ Salmonella typhimurium lysates, $6 \mathrm{mg} \mathrm{SLP}$ or both for $1 \mathrm{~min}$ at $37 \mathrm{C}$. After the incubation, $0 \cdot 2$ volume of ice-cold $20 \%$ perchloric acid was added to the reaction mixture, kept on ice for $20 \mathrm{~min}$ and centrifuged at $2,000 \times \mathrm{g}$ for $20 \mathrm{~min}$ at $4 \mathrm{C}$. The supernatant was titrated to $\mathrm{pH} 7.5$ with 
ice-cold $10 \mathrm{~N} \mathrm{KOH}$ and kept on ice for $15 \mathrm{~min}$. Precipitated $\mathrm{KClO}_{3}$ was removed by centrifugation, and supernatants were applied to Amprep ${ }^{\mathrm{TM}}$ mini columns (Sax $100 \mathrm{mg}$, Amersham Life Science) that had been equilibrated with $5 \mathrm{~mL}$ of $1.0 \mathrm{M} \mathrm{KHCO}_{3}$ and $15 \mathrm{~mL}$ distilled water. Inositol phosphates were eluted using $5 \mathrm{~mL}$ volumes of a discontinuous gradient of $0-0.2 \mathrm{M}$ $\mathrm{KHCO}_{3}$. IP3 was eluted at $0 \cdot 17 \mathrm{M} \mathrm{KHCO}_{3}$. One $\mathrm{mL}$ aliquots of eluent were mixed with $7 \mathrm{~mL}$ scintillation fluid and the radioactivity was determined by $\beta$-scintillation spectroscopy.

\section{PKC Estimation}

The PKC was estimated by the method of Asaoka et al. (1992). Briefly, the mononuclear cells were incubated with $6 \mathrm{mg}$ S. typhimurium lysated, SLP or both for $1 \mathrm{~min}$. Reaction was stopped immediately by adding $5 \mathrm{ml}$ ice-cold HBSS, followed by centrifugation at 2,000 g for $10 \mathrm{~min}$ at $4 \mathrm{C}$. The pellet was brought to the suspension in $0.5 \mathrm{~mL}$ of HBSS and incubated in permeabilization buffer for $10-15 \mathrm{~min}$ at $4 \mathrm{C}$, then centrifuged and washed twice with permeabilization buffer. The anti-PKC antibody was added and cells were incubated for $30 \mathrm{~min}$ at $4 \mathrm{C}$. After the incubation, cells were washed and incubated in secondary antibody for $30 \mathrm{~min}$ at $4 \mathrm{C}$. The cells were then centrifuged and the pellet obtained was brought to suspension, and the fixative was added and incubated at $4 \mathrm{C}$ for $30 \mathrm{~min}$, then analyzed on flow cytometry.

\section{Statistical Analysis}

Statistical significance of difference between the groups or within the group was assessed using a paired or unpaired Student's $t$-test or otherwise as indicated.

\section{RESULTS}

Previously, we have shown that SLP is important for immune modulation. In the present study, we asked the effect of SLP on signaling molecules during infection. First, we look at calcium-signaling, which is known to be involved in pro-inflammatory cytokine induction. The cells isolated from four different groups (as mentioned in Materials and Methods) from the rats exposed to in vivo infection and were further subjected to secondary in vitro stimulation by incubating them with bacterial lysate leads to drastic increase in intracellular calcium, as shown in Fig. 1. On the other hand, the mononuclear cells isolated 

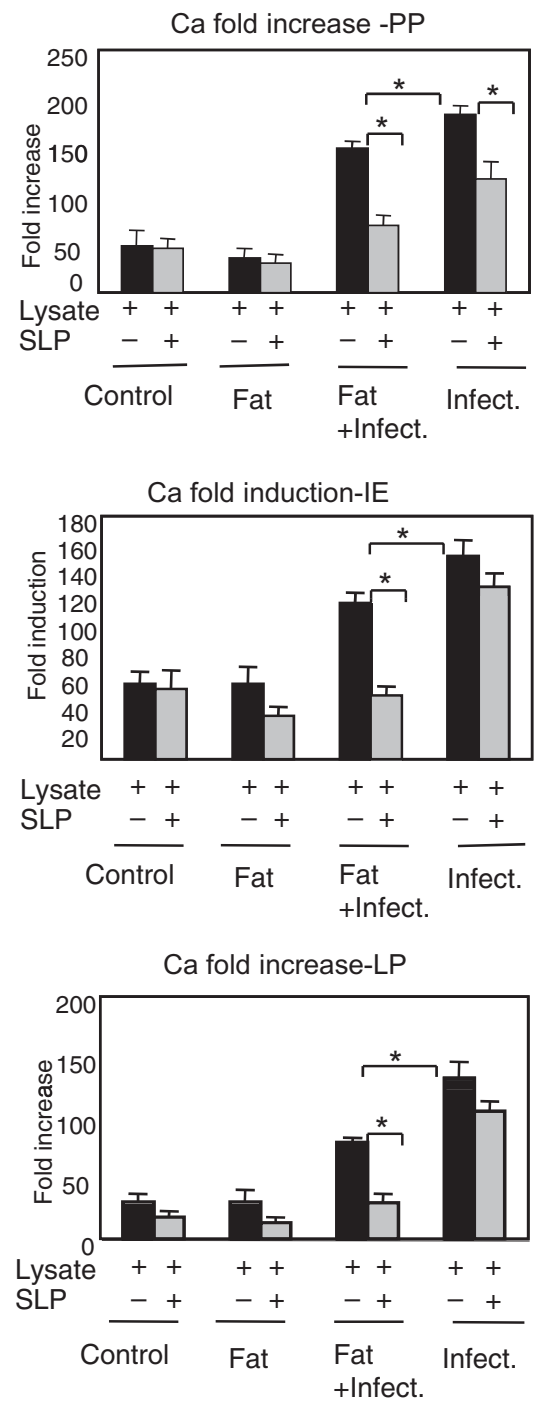

FIG. 1. EFFECT OF SLP ON CALCIUM SIGNALING

Intracellular calcium $\left[\mathrm{Ca}^{2+}\right]_{\mathrm{i}}$ production in mononuclear cells stimulated by $S$. typhimurium lysate alone, SLP alone or both. PP,IE and LP mononuclear cells $\left(1 \times 10^{6}\right.$ cells $\left./ \mathrm{mL}\right)$ from each group were labeled with $4 \mu \mathrm{m}$ fluo 3/AM. These were stimulated with $6 \mu \mathrm{g}$ of cell bacterial lysate alone, $6 \mu \mathrm{g}$ of SLP alone or both together and analyzed on Chronys Software (FL-1 height versus time plot) on flowcytometer. Values are expressed as mean $\pm \mathrm{SD}$ of the cells indicated. *Indicates $P<0.05$. 
from fat-induced SLP, plus infection group and later incubated with bacterial lysate, showed a significant decrease in calcium induction compared with the one from infection alone. These results suggested that the modulation of calcium induction by SLP during Salmonella infection could lead to reduced inflammation. In addition, when the cells were isolated from the infected group, and later incubated in vitro with SLP, showed considerable decrease in calcium level from the PP mononuclear cells only, but not from other cell types, suggesting the most of the effect is on PP mononuclear cell types. Control and SLP diet induced group alone did not show any difference (data not shown).

We next asked if inositol triphosphate has the same effect as has been seen on calcium level. The cells were prepared from all four groups, as mentioned previously, and were analyzed for IP3 level. As shown in Fig. 2, the diet-induced SLP, along with infection, showed a considerable decrease in IP3 level as compared with infection group alone. In addition, the cells isolated from the infected group and incubated in vitro with SLP also showed a comparable decrease in PP mononuclear cells only, suggesting that IP3 and calcium work together, and it seems that SLP have a significant impact on these signaling molecules, especially from PP mononuclear cells.

Next, we asked if PKC has the same effect upon SLP treatment during Salmonella infection. The cells isolated from SLP-induced diet, along with the infected group, showed considerable decrease in the PKC level as compared with the infection-alone group, as shown in Fig. 3. In addition, when the cells isolated from the infected group were later incubated with SLP and analyzed for PKC level, only PP mononuclear cells showed a significant decrease in PKC level as compared to the infection group alone. Together, these results suggested that SLP plays an important role in immune regulation by modulating the secondary signaling molecules. In addition, it was also obvious from the present study that the influence of SLP was more through PP mononuclear cells rather than IE and LP mononuclear cells.

Previous reports have shown a decrease in SLP in active duodenal ulcer or duodenitis, suggesting that SLP is consumed by inflammatory process or that the synthesis/secretion of the SLP had been altered. Next, we sought to know, during the course of infection, the effect on different constituents of SLP. As shown in Table 1, an increase in SLP constituents from the fat-induced SLP group was observed. Surprisingly, there seems to be decreased concentration of SLP during infection. These results suggested the utilization of SLP during an inflammation. Such changes could be of significant importance during infection as an important entity, and could have a significant role during innate immune response. 

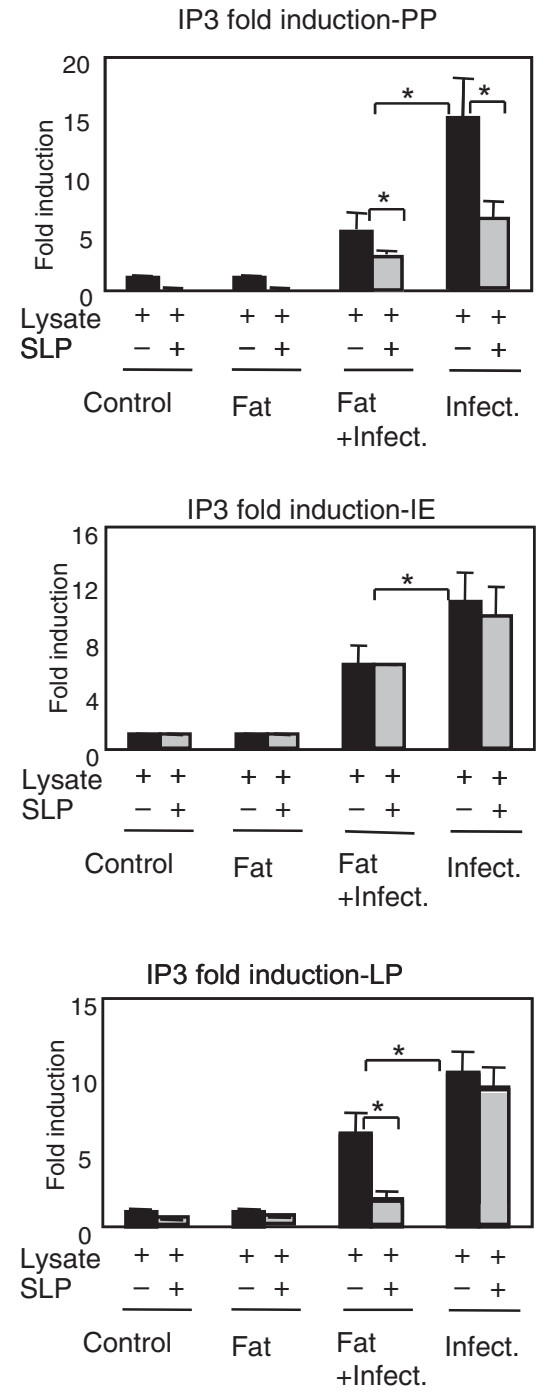

FIG. 2. EFFECT OF SLP ON INOSITOL TRIPHOSPHATE (IP3) TURNOVER

IP3 levels in S. typhimurium cell lysate stimulated mononuclear cells. Mononuclear cells $\left(2 \times 10^{6}\right.$ cells $/ \mathrm{mL}$ ) from each group were labeled with myo- $\left[{ }^{3} \mathrm{H}\right]$-inositol. These were stimulated with $6 \mu \mathrm{g}$ of bacterial lysate alone, with $6 \mu \mathrm{g}$ of SLP alone or both together with $5 \mu \mathrm{g}$ each $(5 \mu \mathrm{g}$ bacterial lysate + $5 \mu \mathrm{g} \mathrm{SLP)}$ and were processed to measure released IP3. Stimulation index is the ratio of CPM of stimulated sample to the CPM of unstimulated sample. Representations and symbols are as in Fig. 2. Values are expressed as mean $\pm \mathrm{SD}$ of the cells indicated. *Indicates $P<0.05$. 

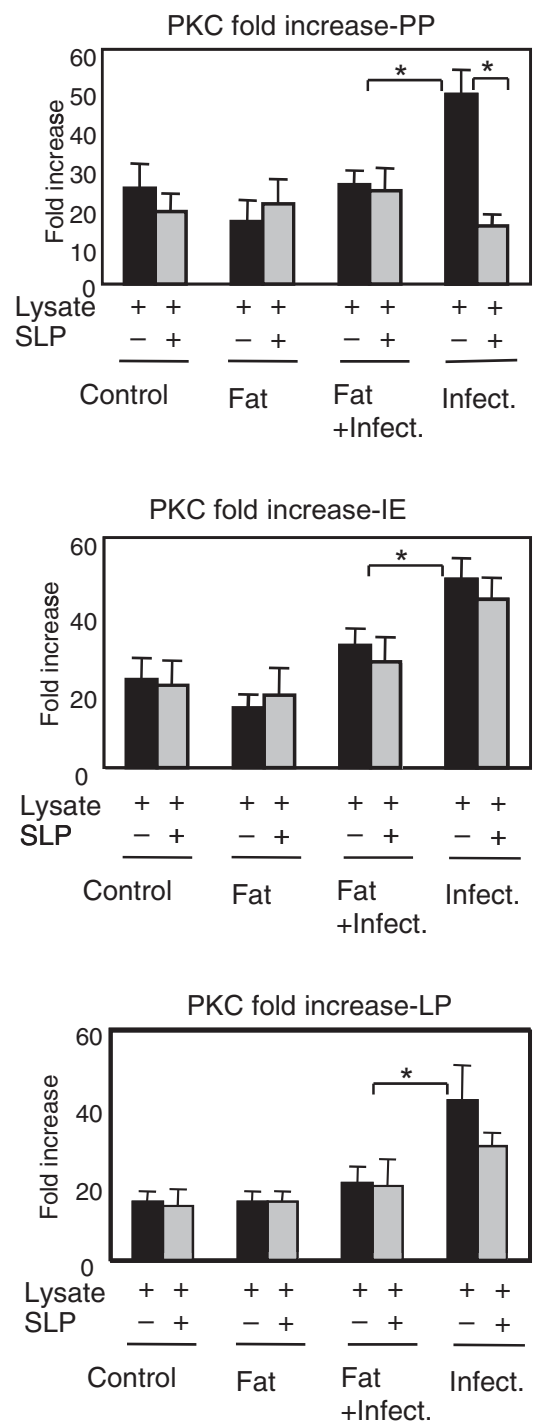

FIG. 3. INFLUENCE OF SLP ON PKC

The protein kinase $\mathrm{C}$ estimation in mononuclear cells stimulated by $S$. typhimurium lysate. PP, IE and LP mononuclear cells were incubated with $6 \mathrm{mg}$ S. typhimurium lysate, SLP or both for $10 \mathrm{~min}$. Reaction was stopped immediately by adding $5 \mathrm{~mL}$ ice cold HBSS followed by centrifugation. Cells were stained with anti-PKC antibody and analyzed on flow cytometry. The experiment is representative of one of three independent experiments. Values are expressed as mean $\pm \mathrm{SD}$ of the cells indicated.

*Indicates $P<0.05$. 
TABLE 1.

EXPRESSION LEVEL OF DIFFERENT CONSTITUENTS OF SLP UNDER DIFFERENT CONDITIONS

\begin{tabular}{llll}
\hline Group/levels & $\begin{array}{l}\text { Alkaline phospatase } \\
\text { KAU/mg protein }\end{array}$ & $\begin{array}{l}\text { Protein } \\
\mathrm{mg} / \mathrm{mL}\end{array}$ & $\begin{array}{l}\text { Phospholipid } \\
\mathrm{mg} / \mathrm{mL}\end{array}$ \\
\hline Control & $4.80 \pm 0.30$ & $0.20 \pm 0.07$ & $0.86 \pm 0.06$ \\
Fat diet & $9.91 \pm 0.71$ & $0.43 \pm 0.01$ & $1.71 \pm 0.03$ \\
Fat diet + Infection & $3.62 \pm 0.23$ & $0.26 \pm 0.09$ & $0.99 \pm 0.01$ \\
Infection & $1.11 \pm 0.09$ & $0.17 \pm 0.01$ & $0.78 \pm 0.09$ \\
\hline
\end{tabular}

The different constituents of SLP varies under different condition. Upon fat feeding (corn oil) to the mice, a drastic increase in different constituents of SLP were observed as compared to controls (basal level), fat plus infection and infection alone group.

\section{DISCUSSION}

SLP induced by dietary fat-enhanced the resistance to intestinal infections, as it possibly decreases the colonization and translocation of $S$. typhimurium. The SLP microbe interaction may represent a delicate balance between symbiosis and pathogenesis.

Nutritional status may have significant importance for the immune system. Particularly, unsaturated fatty acids may serve as modulators of immune function. Clinical and epidemiological studies have shown that fatty acids are involved in the reduction of the inflammatory processes that occur in the disease characterized by over-activation of the immune system. It has also been reported that invasion and adhesion were reduced in the cells from mice fed with fish oil diet (Puertollano et al. 2002), and fish oil is known to be rich source for SLP induction.

Previous reports have identified signaling events by which an important enteric pathogen induces the intestinal epithelium to orchestrate a mucosal inflammation. In response to $S$. typhimurium infection, the intestinal epithelium activates the immuno-modulatory transcription factor by a mechanism involving increases in intracellular calcium(Gewirtz et al. 2000). Because the clinical manifestations of Salmonellosis result primarily from the inflammatory response to this pathogen (Mccormick et al. 1998), these events appear essential to the pathogenesis of this infectious disease. Thus, it is clear now that the first step in pathogenesis is the attachment of pathogen to the intestinal epithelium. Reports have shown that SLP in the intestinal lumen covers the surface of the cells. Recently, our group has published a report in which it was shown that SLP modulates the proinflammatory cytokines during S. typhimurium infection (Sofi et al. 2007). This observation was further supported by electron microscopic studies, which showed only broadening and shortening of the microvilli of the intestine in rats given SLP-induced diet along with the 
infection, as compared to the infected group, in which microvilli was fully damaged after infection (Sofi et al. 2007). In the present study, we observe the modulation of secondary signaling molecules from the group given the infection along with SLP-induced diet, suggesting the involvement of this molecule in immuno-modulation during infection. We found that SLP downregulates the secondary signaling cascade, especially IP3, calcium and PKC from the group where both SLP-induced diet along with infection was given, as compared to the infection alone group. The effect was more drastic on PP mononuclear cells. In addition, we also observed that the cells isolated from the infected group alone, upon incubation in in vitro with SLP, showed a significant decrease in these secondary signaling molecules, particularly in PP mononuclear cells. These findings suggested that SLP plays an important role in regulating secondary signaling molecules, which finally could have a greater impact on cytokine status and on overall immune response. One possible reason for this modulation could be that SLP prevents the interaction between the pathogen and the epithelial layer. Involvement of SLP in this kind of immune response can be speculated in the light of a similar study, where adhesion of uropathogenic $E$. coli is mediated at the tips of the pilli by the papG adhesion in presence of SLP (Mahmood et al. 2000).

S. typhimurium attachment induces an increase in cytosolic IP3 in eukaryotic cells (Bertelsen et al. 2004), which, in turn, elicits calcium release from intracellular stores, followed by calcium influx. The induction of the IP3 in the present study correlates with previous reports. However, the decrease in IP3 level in SLP-induced diet along with infection suggests a correlation between IP3 and calcium signaling. These results provide new insight regarding the SLP's role during infection. A similar kind of effect was also observed from PKC. The utilization of SLP/or decrease in SLP content during infection confirms the involvement of SLP in such atmosphere. These are just observations, and further study is warranted in this direction. This time, we do not know how SLP functions. Is it directly binding the pathogen and in turn reducing the induction of proinflammatory cytokines, as seen in our previous reports, or is there an alternative way by which it works? These are the questions that need to be addressed to pave the way for its utilization during infection/or as a therapeutic agent.

\section{REFERENCES}

ASAOKA, Y., OKA, M., YOSHIDA, K., SASAKI, Y. and NISHIZUKA, Y. 1992. Role of lysophosphatidylcholine in T-lymphocyte activation: involvement of phospholipase A2 in signal transduction through protein kinase C. Proc. Natl. Acad. Sci. U. S. A. 89, 6447-6451. 
BERTELSEN, L.S., PAESOLD, G., MARCUS, S.L., FINLAY, B.B., ECKMANN, L. and BARRETT, K.E. 2004. Modulation of chloride secretory responses and barrier function of intestinal epithelial cells by the Salmonella effector protein SigD. Am. J. Physiol. Cell. Physiol. 287, C939-C948.

DAVIES, M.D. and PARROTT, D.M. 1981. Preparation and purification of lymphocytes from the epithelium and lamina propria of murine small intestine. Gut 22, 481-488.

ELIAKIM, R., DESCHRYVER-KECSKEMETI, K., NOGEE, L., STENSON, W.F. and ALPERS, D.H. 1989. Isolation and characterization of a small intestinal surfactant-like particle containing alkaline phosphatase and other digestive enzymes. J. Biol. Chem. 264, 20614-20619.

ELIAKIM, R., ALPERS, D.H., OREN, R., FICH, A. and DESCHRYVERKECSKEMETI, K. 1996. Abundance of surfactant-like particles reflects mucosal integrity in patients with peptic ulcer disease. Gut 39, 353359.

GEWIRTZ, A.T., RAO, A.S., SIMON, P.O., JR, MERLIN, D., CARNES, D., MADARA, J.L. and NEISH, A.S. 2000. Salmonella typhimurium induces epithelial IL-8 expression via $\mathrm{Ca}(2+)$-mediated activation of the NF-kappaB pathway. J. Clin. Invest. 105, 79-92.

GOETZ, G.S., MAHMOOD, A., HULTGREN, S.J., ENGLE, M.J., DODSON, K. and ALPERS, D.H. 1999. Binding of pili from uropathogenic Escherichia coli to membranes secreted by human colonocytes and enterocytes. Infect. Immun. 67, 6161-6163.

KING, E.J. and AMSTRONG, A.R. 1934. Determination of serum and bile phosphatase activity. J. Can. Med. Assoc. 31, 376-379.

KOHLER, H., SAKAGUCHI, T., HURLEY, B.P., KASE, B.A., REINECKER, H.C. and MCCORMICK, B.A. 2007. Salmonella enterica serovar Typhimurium regulates intercellular junction proteins and facilitates transepithelial neutrophil and bacterial passage. Am. J. Physiol. Gastrointest. Liver Physiol. 293, G178-G187.

LOWRY, O.H., ROSE, N.J., FARR, A.L. and RANDELL, R.J. 1951. Protein measurements with the folin-phenol reagent. J. Biol. Chem. 193, 265275.

LYSCOM, N. and BRUETON, M.J. 1982. Intraepithelial, lamina propria and Peyer's patch lymphocytes of the rat small intestine: isolation and characterization in terms of immunoglobulin markers and receptors for monoclonal antibodies. Immunology 45, 775-783.

McCORMICK, B.A., PARKOS, C.A., COLGAN, S.P., CARNES, D.K. and MADARA, J.L. 1998. Apical secretion of a pathogen-elicited epithelial chemoattractant activity in response to surface colonization of intestinal epithelia by Salmonella typhimurium. J. Immunol. 160, 455-466. 
MAHMOOD, A., ENGLE, M.J., HULTGREN, S.J., GOETZ, G.S., DODSON, K. and ALPERS, D.H. 2000. Role of intestinal surfactant-like particles as a potential reservoir of uropathogenic Escherichia coli. Biochim. Biophys. Acta 1523, 49-55.

MAHMOOD, A., SHAO, J.S. and ALPERS, D.H. 2003. Rat enterocytes secrete SLPs containing alkaline phosphatase and cubilin in response to corn oil feeding. Am. J. Physiol. Gastrointest. Liver Physiol. 285, G433G441.

MINTA, A., KAO, J.P. and TSIEN, R.Y. 1989. Fluorescent indicators for cytosolic calcium based on rhodamine and fluorescein chromophores. J. Biol. Chem. 264, 8171-8178.

OLDHAM, K.G. 1990. Polyphosphoinositide turnover. In Receptor-Effector Coupling - A Practical Approach (E.C. HULME, ed.) Oxford University Press, Oxford.

POWELL, D.W., PLOTKIN, G.R., MAENZA, R.M., SOLBERG, L.I., CATLIN, D.H. and FORMAL, S.B. 1971. Experimental diarrhea. I. Intestinal water and electrolyte transport in rat salmonella enterocolitis. Gastroenterology 60, 1053-1064.

PUERTOLLANO, M.A., DE PABLO, M.A. and ALVAREZ DE CIENFUEGOS, G. 2002. Relevance of dietary lipids as modulators of immune functions in cells infected with Listeria monocytogenes. Clin. Diagn. Lab. Immunol. 9, 352-357.

SEARS, C.L. 2000. Molecular physiology and pathophysiology of tight junctions V. assault of the tight junction by enteric pathogens. Am. J. Physiol. Gastrointest. Liver Physiol. 279, G1129-G1134.

SOFI, M.H., BHATNAGAR, A., SAPRA, S., MAHMOOD, A. and MAJUMDAR, S. 2007. Immunoregulatory role of intestinal surfactant-like particles during Salmonella typhimurium infection. Int. J. Biol. Sci. 3, 446-454.

ZHANG, T. and STANLEY, S.L., JR 1996. Oral immunization with an attenuated vaccine strain of Salmonella typhimurium expressing the serine-rich Entamoeba histolytica protein induces an antiamebic immune response and protects gerbils from amebic liver abscess. Infect. Immun. 64, 15261531. 